\title{
Behaviour influences larval dispersal in shelf sea gyres: Nephrops norvegicus in the Irish Sea
}

\author{
Jack J. C. Phelps ${ }^{1, *}$, Jeff A. Polton ${ }^{1}$, Alejandro J. Souza ${ }^{1}$, Leonie A. Robinson ${ }^{2}$ \\ ${ }^{1}$ National Oceanography Centre, Joseph Proudman Building, 6 Brownlow Street, Liverpool L3 5DA, UK \\ ${ }^{2}$ University of Liverpool, Nicholson Building, Liverpool L69 3GP, UK
}

\begin{abstract}
The western Irish Sea seasonal gyre is widely thought to play an important role in the local retention of resident larvae. This mechanism could be particularly crucial for the larvae of the heavily fished crustacean Nephrops norvegicus (L.), as their sediment requirements highly restrict where they are able to settle. Recent research suggests that the gyre may be becoming less retentive due to changes in atmospheric forcing; thus it is now crucial to understand how the gyre influences larval dispersal. This investigation addresses the hypothesis that shelf sea gyres reinforce larval retention, using a biophysical model with vertical migration, habitat selection and temperature-dependent pelagic larval duration (PLD) configured to match the behaviour of $N$. norvegicus larvae. The results suggest that the gyre does increase the likelihood that passive larvae remain within the western Irish Sea when the larvae remain fixed at the depth of peak gyral flow. However, retention rates are significantly lower when vertical migration is introduced, and there is no evidence that the gyre promotes larval retention amongst either vertically migrating larvae, or larvae that require muddy sediments for successful settlement. In contrast, vertical migration is shown to be favourable for local retention in the eastern Irish Sea. PLD varies by a factor of 2 according to release date and location. The simulations suggest that whilst some highly limited and almost entirely unidirectional larval exchange may occur, the distinct sites largely rely upon local recruitment.
\end{abstract}

KEY WORDS: 3D numerical modeling · Connectivity · Decapod crustaceans · Gyre $\cdot$ Irish Sea · Larval dispersal $\cdot$ Nephrops norvegicus $\cdot$ Zooplankton

\section{INTRODUCTION}

Nephrops norvegicus (L.) is a heavily fished, benthic decapod crustacean that inhabits muddy sublittoral sediments throughout European continental shelf seas (Farmer 1975). The meroplanktonic larval phase of $N$. norvegicus in the western Irish Sea has been of considerable interest since the discovery of a strong seasonal baroclinic gyre that encircles a region inhabited by the adult population (Hill et al. 1994). The larvae generally hatch during April and May every year (DickeyCollas et al. 2000a), pass through 3 distinct zoeal larval stages (Farmer 1975), and have a temperature-

${ }^{*}$ Corresponding author: jack.phelps@liverpool.ac.uk dependent pelagic larval duration (PLD) that ranges from $\sim 72 \mathrm{~d}$ at $8^{\circ} \mathrm{C}$ to $26 \mathrm{~d}$ at $15^{\circ} \mathrm{C}$ (Smith 1987, Dickey-Collas et al. 2000b). Adult N. norvegicus require muddy sediments in order to construct their burrows, and the spatial distribution of these sediments places a major constraint on where the larvae are able to settle. Any larvae that are unable to find a suitable habitat at the end of their larval phase are assumed to fall to mortality. After observing that drifting buoys were retained in the gyral system, Hill et al. (1996) proposed that the seasonal gyre may act to retain the larvae within the waters overlying these muddy sediments, ultimately promoting self-recruitment.

() The authors and Natural Environment Research Coucil 2015. Open Access under Creative Commons by Attribution Licence. Use, distribution and reproduction are unrestricted. Authors and original publication must be credited.

Publisher: Inter-Research · www.int-res.com 
The western Irish Sea gyre has since been a focal point of numerous observational (Hill et al. 1997, Horsburgh et al. 2000), theoretical (Hill 1996) and numerical (Xing \& Davies 2001, Horsburgh \& Hill 2003) investigations, and the timing, strength and drivers of the gyre are now relatively well established. A dense cold-water pool forms early each spring, trapped beneath a sharp seasonal thermocline and isolated from adjacent bottom waters by abrupt bottom density fronts. This density field is stable due to strong surface heat fluxes and weak tidal energy (Simpson \& Hunter 1974). As a result of geostrophy, the bottom density gradients induce a cyclonic velocity field, with peak flows at the thermocline $24 \mathrm{~m}$ below the surface. Cyclonic circulation is observed as early in the year as April, then the strength of the gyre develops gradually as bottom density gradients sharpen, reaching peak velocities of $0.2 \mathrm{~m} \mathrm{~s}^{-1}$ during August, and the gyre finally breaks down during October (Horsburgh et al. 2000). A recent modelling investigation found evidence to suggest that there is a long-term trend in the dynamics of the gyre due to changes in atmospheric conditions, resulting in a stronger, but less retentive gyre (Olbert et al. 2011). The long-term mean flow through the Irish Sea is considered to be weak $\left(<0.01 \mathrm{~m} \mathrm{~s}^{-1}\right)$ and northwards (Bowden 1950, Wilson 1974).

Although the physical environment in the western Irish Sea may be well understood, many of the assumptions about larval transport in the region are derived either from passive fixed-depth drifting buoys, or directly from the mean circulation. There is now a substantial body of evidence to demonstrate that the meroplanktonic larvae of marine invertebrates are able to manipulate their depth within the water column (e.g. Cushing 1951, Cronin \& Forward 1979, Forward et al. 1984, Lindley et al. 1994, Knights et al. 2006), and that this mechanism may influence their trajectory (Hill 1991, Smith \& Stoner 1993, North et al. 2008, Sundelof \& Jonsson 2012); therefore larvae should not be regarded as entirely passive. In regions with a strong vertical velocity shear, swimming vertically just a few metres may result in vastly different dispersal scenarios (Vikebo et al. 2005). N. norvegicus larvae are thought to migrate vertically according to time of day (diel vertical migration or DVM) and larval stage (ontogenetic migration) (Hillis 1974, Lindley et al. 1994); therefore caution should be taken when drawing conclusions from passive, fixed-depth drifters. Furthermore, the gyre has been described as 'leaky', as not all drifting buoys are entrained within the gyre (Hill et al. 1994,
1997). Horsburgh et al. (2000) reported that loss from the gyral system is particularly likely during the early stages of the heating season in May and early June. This period corresponds to the latest stages of the $N$. norvegicus hatching window (Dickey-Collas et al. 2000a); therefore some loss of larvae from the gyral system may be anticipated. This is supported by larval surveys that show the occurrence of larvae outside the muddy sediment regions inhabited by adult N. norvegicus (Hillis 1974, White et al. 1988).

Whilst each of these studies have contributed to our understanding of larval dispersal in this region, evidence that the gyre acts as an effective retention mechanism for planktonic larvae with complex behaviour remains inconclusive. It is clear that there are still numerous questions regarding the migration of western Irish Sea N. norvegicus larvae, and more generally, the relationship between planktonic larvae and shelf sea gyres. We are able to draw some insight from larval surveys (Hillis 1974, Nichols et al. 1987, White et al. 1988, Horsburgh et al. 2000) and other modelling studies (e.g. Emsley et al. 2005, Fox et al. 2006, 2009, van der Molen et al. 2007, Robins et al. 2013) that address larval transport in the Irish Sea, and some of these studies are discussed in greater detail later. However, ours is the first investigation to utilise a 3-dimensional hydrodynamic model coupled to an individual based model (IBM), where the vertical migration behaviour, temperature-dependant PLD and settlement requirements are each parameterised specifically to match the behaviour of $N$. norvegicus larvae. As the influence of the western Irish Sea gyre upon $N$. norvegicus transport is one of the most frequently cited examples of a biophysical interaction between planktonic larvae and local density-driven flow, there is clearly a great need for a detailed and focused investigation on the subject.

The principal objective here is to examine spatial and temporal variability of larval dispersal distance and retention rates in 2 regions in the Irish Sea inhabited by N. norvegicus (Fig. 1), and to determine how these factors are affected by larval behaviour. The results are then scrutinised to establish whether they support the larval retention hypothesis of Hill et al. (1996). Additionally, the extent of particle exchange between the distinct regions is assessed in order to identify whether the simulations are consistent with a collection of metapopulations connected through larval exchange, or isolated $N$. norvegicus populations where self-recruitment dominates.

This investigation also presents an opportunity to study the PLD of $N$. norvegicus. Larval culture studies (e.g. Thompson \& Ayers 1989, Dickey-Collas et al. 

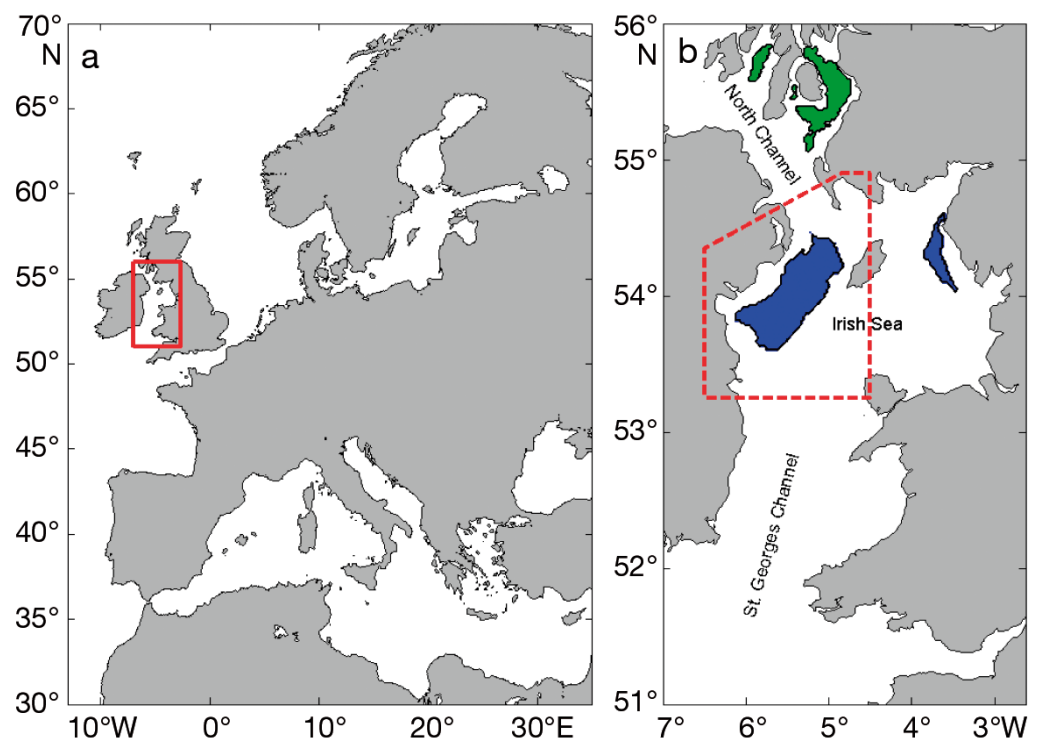

Fig. 1. Proudman Oceanographic Laboratory Coastal Ocean Modelling System (POLCOMS) Irish Sea model domain shown (a) within the European continental shelf; (b) with the locations of the Irish Sea muddy sediments (where particles are initialised) (blue), the additional North Channel muddy sediments (green), and the western Irish Sea region (dashed red line)

\section{METHODS}

\section{Hydrodynamic model}

The Proudman Oceanographic Laboratory Coastal Ocean Modelling System (POLCOMS) hydrodynamic model is used to provide sea surface elevation and 3-dimensional fields of velocity, temperature and vertical diffusivity to an IBM. POLCOMS operates upon a staggered Arakawa B-grid (Arakawa \& Lamb 1977) in the horizontal, with terrain following $\sigma$-coordinates in the vertical. The model adopts the piecewise parabolic method (PPM) (Colella \& Woodward 1984), which allows for artificial steepening of gradients, and is highly regarded by shelf sea modellers for its relatively low numerical diffusivity (James 1996). The combination of the PPM advection scheme and the Arakawa B-grid

2000b) provide excellent ways to determine PLD from temperature; however, temperature is not uniform in reality. As the larvae migrate vertically through a sharp thermocline, they may be subject to daily temperature changes of several degrees Celsius, making it very difficult to estimate PLD in the field. In this investigation, larval growth rates were determined from these temperature relations, which allowed us to estimate the spatial and temporal variability in PLD. As sea surface temperature increases gradually over the heating season, the PLD of larvae can be expected to decrease. As a shorter PLD is generally associated with a shorter dispersal distance (Shanks et al. 2003, Cowen \& Sponaugle 2009), this could lead to greater retention rates amongst larvae that hatch later in the season, and perhaps reinforce a seasonal asymmetry caused by the strengthening gyre.

Whilst this investigation focuses upon the Irish Sea, Horsburgh et al. (2000) note that isolated cold-water pools have been identified across the world, and that numerical models suggest cyclonic flow fields in some cases. Additionally, the co-occurrence of the western Irish Sea gyre and the muddy sediment is not coincidental, both are consequences of weak local tidal energy. As many benthic species are selective about habitat, retention of $N$. norvegicus larvae in the western Irish Sea could be a particular case of a more general process. ensure that sharp gradients such as tidal mixing fronts are not eroded in the advection process, making the model particularly suitable for modelling the western Irish Sea gyre. Atmospheric forcing is calculated with the Coupled Ocean-Atmosphere Response Experiment (COARE) 3.0 bulk formulae (Fairall et al. 2003) using $1^{\circ}$ and 6 hourly European Center for Medium-Range Weather Forecasts (ECMWF) wind and surface flux data. Tidal velocities and elevations are fully resolved, and are forced at the open boundaries.

The POLCOMS Irish Sea set-up is used for the current study, a high-resolution $(\sim 1.8 \mathrm{~km}$ horizontal resolution, $32 \sigma$-coordinate layers) model of a shelf sea region containing the whole Irish Sea, St George's Channel and the North Channel $\left(7^{\circ}\right.$ to $2.6^{\circ} \mathrm{W}, 51^{\circ}$ to $56^{\circ} \mathrm{N}$, see Fig. 1). The Irish Sea setup is well documented and has been utilised to study shelf sea processes within numerous recent modelling investigations (e.g. Polton et al. 2011, O'Neill et al. 2012, Phelps et al. 2013). Further technical details of POLCOMS are provided by Holt \& James (2001).

POLCOMS is coupled to the General Ocean Turbulence Model (GOTM) (Umlauf \& Burchard 2003) which allows the user to choose from a selection of turbulence closure schemes. The k- $\varepsilon$ closure scheme (Canuto et al. 2001) is used throughout this investigation. 


\section{Particle-tracking model}

The IBM is an offline 3-dimensional Lagrangian particle-tracking model with additional subroutines to parameterise vertical migration behaviour, settlement and a temperature-dependant PLD, and was developed specifically for this investigation following the guidelines provided by North et al. (2009) and Willis (2011). Sea surface elevation and velocity are updated every $300 \mathrm{~s}$, and are interpolated linearly in time and bilinearly in space to give values at the location of each particle. Particle advection is calculated using Runge-Kutta fourth order integration (RK4) with advection time step of $60 \mathrm{~s}$. RK4 is a stable and reliable multi-step method for numerical integration, and the benefits of RK4 over simpler integration schemes (such as Euler or second-order RungeKutta methods) are widely documented (e.g. North et al. 2009, Qiu et al. 2011).

Temperature and vertical diffusivity are updated once every $600 \mathrm{~s}$, and a cubic smoothing spline is fitted vertically to the discrete diffusivity values, ensuring that both diffusivity and its first derivative are smooth, and that the second derivative is continuous throughout the water column. Vertical diffusion is calculated using the random walk model described by Ross \& Sharples (2004) (but also see Hunter et al. 1993, Visser 1997), which includes additional terms to prevent artificial particle accumulation in regions of low diffusivity. The diffusion component of the model uses a time step of $6 \mathrm{~s}$. Reflective boundary conditions are placed at the sea surface, bottom and land boundaries to prevent particles leaving the water column. Any particles that are advected beyond the model domain through the open boundaries are removed from the system.

\section{Larval behaviour sub-model}

The vertical migration component of the larval behaviour sub-model is based upon the correlated random walk model described by North et al. (2008). As there is little direct evidence of the swimming capabilities of $N$. norvegicus larvae, parameters were determined using a 1-dimensional model to ensure that vertical density profiles were qualitatively similar to those recorded by Hillis (1974) and Lindley et al. (1994).

The maximum swimming speed of each particle increases from $1 \mathrm{~mm} \mathrm{~s}^{-1}$ during the first larval stage to $3 \mathrm{~mm} \mathrm{~s}^{-1}$ in the final stage. This swimming speed is then multiplied by a random number taken from the continuous uniform distribution $\mathrm{U}[0,1]$, reflecting the variability of larval swimming speed. Although some decapod larvae are capable of swimming at greater speeds in reality (Kingsford et al. 2002), it is the vertical profiles that will influence horizontal trajectories rather than swimming velocity itself. Finally, the direction of particle movement is determined using a stochastic scheme, whereby swimming velocity is directed upwards if a second random number taken from $U[0,1]$ exceeds a weighted parameter $\lambda$, and downwards otherwise. The weighted parameter $\lambda$ is a function of larval stage, time of day and depth in the water column, and is used to control the mean characteristics of particle swimming. The precise mathematical calculation of $\lambda$ is given in the Appendix.

Particles are forced to ascend towards the surface shortly after hatching, and then they migrate vertically about a mean position each day, reaching their highest point in the water column each midnight, and descending to their deepest point at midday (Fig. 2). The particles continue this DVM pattern throughout their PLD, but they are gradually permitted to descend into slightly deeper waters, until the second

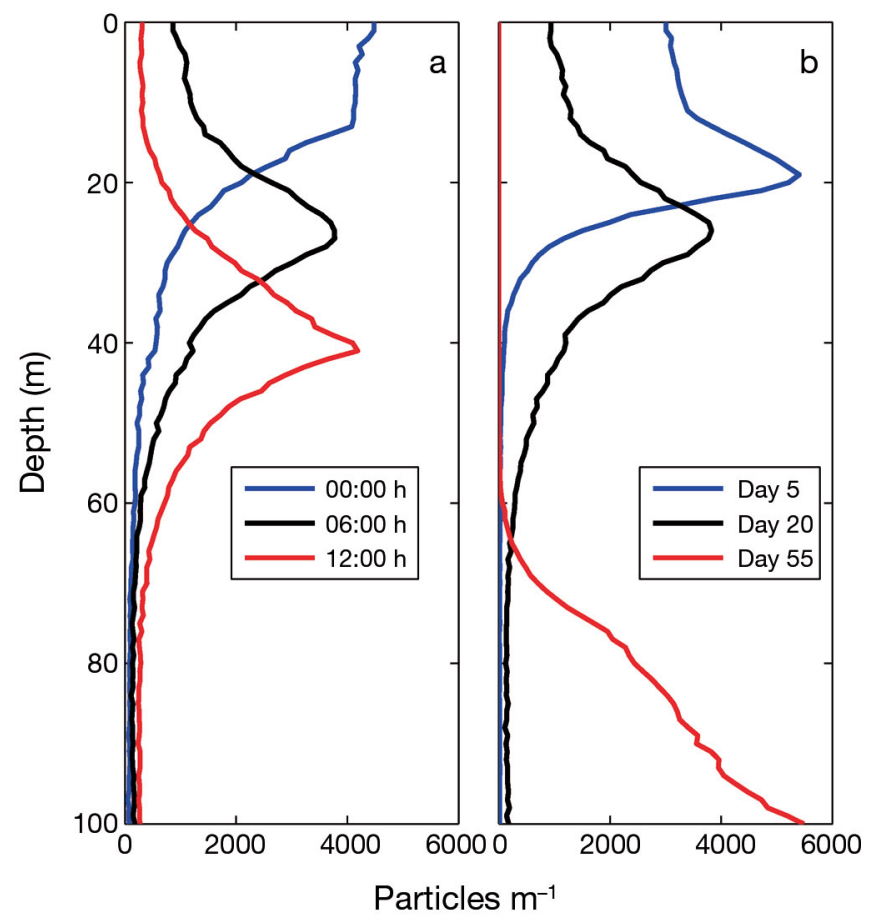

Fig. 2. One-dimensional model simulation where 10000 particles are released and tracked for $60 \mathrm{~d}$. Depths are governed by vertical diffusion and swimming behaviour. (a) Particle density profile at 3 different times on Day 20, showing diel vertical migration. (b) Particle density profile at 3 different stages of the pelagic phase, each at 06:00 h, showing ontogenetic migration. Note that particles are released in unison, whereas larval density profiles in field observations show larvae with a range of ages 
half of their final larval stage when they begin to swim directly towards the seabed.

The PLD of many marine species are highly dependent upon water temperature (O'Connor et al. 2007). Several larval culture studies have aimed to establish the precise relationship between $N$. norvegicus PLD and temperature, and these are summarised in Powell \& Eriksson (2013). For this investigation we adopt the parameters of Dickey-Collas et al. (2000b) for larval stages 1 and 2, Smith (1987) for stage 3 following Dickey-Collas et al. (2000a). The duration $\theta_{i}(\mathrm{~d})$ of larval stage $i$ can be approximated by the following function of seawater temperature $T\left({ }^{\circ} \mathrm{C}\right)$.

$$
\theta_{i}= \begin{cases}\exp (4.265-0.161 T), & \text { if } i=1 \\ \exp (4.646-0.175 T), & \text { if } i=2 \\ \exp (4.188-0.113 T), & \text { if } i=3\end{cases}
$$

This function assumes that temperature is constant throughout each larval stage; however, in practice the spatial and temporal variability in coastal regions is often too great to be ignored (see Fig. 3). The seawater temperature surrounding a moving particle will vary according to time $t$ and particle location $x$, which in turn can also be regarded as function of time $x=x(t)$. As such, the duration of larval stage $i$ for a particle can be rewritten as a function of time:

$$
\theta_{i}(t)=\exp \left(a_{i}+b_{i} T(t)\right)
$$

where the coefficients $a_{i}$ and $b_{i}$ are as in Eq. (1). To account for this variability in temperature, each particle is allocated a normalised stage duration, $\tau_{i}$, that increases according to:

$$
\frac{\mathrm{d} \tau_{i}}{\mathrm{~d} t}=\frac{1}{\theta_{i}(t)}
$$

where a particle enters larval stage $i$ at time $t_{i}$, such that $\tau_{i}\left(t_{i}\right)=0$, and enters the following larval stage $i+$ 1 , at a time $t_{i+1}$, such that $\tau_{i}\left(t_{i}\right)=1$. Note that $t_{1}$ corresponds to the particle release time and if the particles pass through $n$ distinct larval stages ( $n=3$ for $N$. norvegicus), $t_{n+1}$ represents the settlement time. The total PLD of each particle is therefore equal to $t_{n+1}-$ $t_{1}$. Also note that in the special case of uniform temperature, the stage durations of Dickey-Collas et al. (2000a) and Smith (1987) still apply. The temperature relations derive from larval culture studies where the larvae are typically held at a constant temperature; therefore it is not clear how a variable temperature would affect the PLD in reality. The method used here is a practical way to incorporate these relations into a variable environment. Similar methods have been used previously to simulate the larvae of other species (e.g. Nicolle et al. 2013).
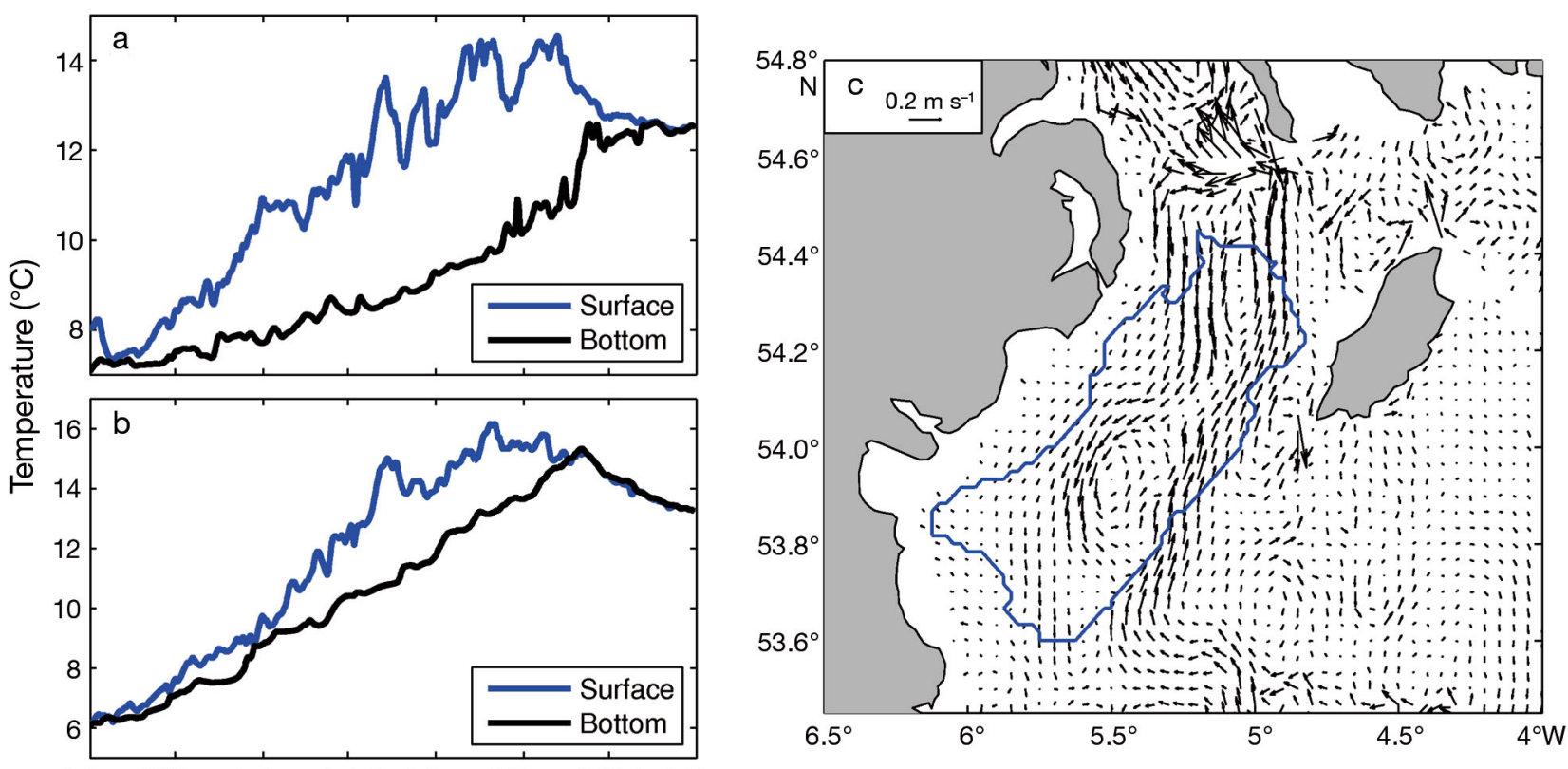

1 Apr 1 May 1 Jun 1 Jul 1 Aug 1 Sep 1 Oct 1 Nov

Fig. 3. Temperature time series from POLCOMS output for the (a) western Irish Sea $\left(54^{\circ} \mathrm{N}, 5.4^{\circ} \mathrm{E}\right)$ and (b) eastern Irish Sea $\left(54.3^{\circ} \mathrm{N}, 3.75^{\circ} \mathrm{E}\right)$; temperatures have been passed through a central moving average filter to reduce the signal from semi-diurnal tidal advection. (c) Monthly mean circulation in the western Irish Sea at $24 \mathrm{~m}$ depth for June 2005 shown at every fourth grid cell. Arrow length is proportional to absolute velocity; the blue contour delineates the muddy sediments. Note that gyre strength is greater in July-August; however N. norvegicus larvae are more abundant in May-June 
At the end of the final larval stage, particles remain pelagic for up to one additional day and settle upon impact with the muddy sediments. Particles are not able to settle prior to this period, and any particles that have not encountered suitable substrate by the end of this period are removed from the system.

Mortality of $N$. norvegicus larvae is highly complex, due to predation and parasites (Farmer 1975). Although estimates of average daily larval mortality rates are available (Nichols et al. 1987, Dickey-Collas et al. 2000a, Briggs et al. 2002), little is known about how mortality varies spatially and temporally. Mortality is therefore neglected entirely in this investigation. This also ensures that a far greater number of particles are available for statistical analysis. However, in reality mortality will diminish recruitment rates considerably; it is likely that mortality will not have a uniform effect and this would influence results. This is not a problem here as this investigation is chiefly concerned with the influence of the physical environment and vertical migration upon dispersal.

\section{Model set-ups and analyses}

Particles are initially distributed uniformly across the western and eastern Irish Sea muddy sediments (Fig. 1, blue regions), with $>170000$ particles in total over both regions for each simulation. This is repeated for 6 different release dates, with 3 different model set-ups. The number of particles was confirmed to be sufficient in a sensitivity analysis (repeated simulations had median dispersal distances that differed by less than $0.1 \mathrm{~km}$, and connectivity statistics differed by less than $0.1 \%$ ). In a similar study, Robins et al. (2013) deemed that 10000 particles per site were sufficient for modelling larval dispersal in the Irish Sea. Some observations strongly indicate that in reality the western Irish Sea $N$. norvegicus group is spatially inhomogeneous, with peak densities in the centre of the region (Hillis 1974, White et al. 1988); however the lack of available quantitative data on the distribution of adult $N$. norvegicus makes it very difficult to accurately replicate the true hatching pattern in the model. This is not a problem as this investigation is primarily concerned with spatial and seasonal variability of larval dispersal, rather than providing population mean values.

In the model, the particles are initially released on April 15, and then every $10 \mathrm{~d}$ until June 4, using meteorological data from the year 2005. These dates span the hatching season of $N$. norvegicus larvae
(Dickey-Collas et al. 2000a). Each particle is introduced into the water column at a random time on the allocated release date to minimise the influence of initial tidal state on the overall results.

No particles are released from the additional muddy sediments in the Scottish coastal waters adjacent to the North Channel (Fig. 1, green regions) as they are in close proximity to the model boundary, and large numbers of particles would almost certainly leave the model domain. The model runs are therefore able to investigate larval exchange in both directions between the eastern and western Irish Sea, but only 1-way connectivity to the North Channel. As the mean circulation through the Irish Sea is predominantly northwards, one would assume that larval transport from the North Channel into the Irish Sea is rather unlikely.

In order to investigate the influence of larval behaviour, 3 model set-ups are used, and elements of the larval behaviour sub-model are introduced in stages. In model set-up (1) (fixed-depth), particles are fixed at $24 \mathrm{~m}$ depth in the vertical (equal to the depth of the fixed drifting buoys in Horsburgh et al. [2000], and the approximate depth of the thermocline) throughout their PLD, or fractionally above the seabed, where depths are shallower than $24 \mathrm{~m}$. Each particle is tracked for $60 \mathrm{~d}$. In model set-up (2) (active-depth), particles are released from the seabed; their depth is subsequently governed by stochastic diffusion and vertical migration, and particles are again tracked for $60 \mathrm{~d}$. Model set-up (3) (fullmodel) is equivalent to the active-depth set-up, except that PLD is determined by water temperature using Eqs. (2) \& (3).

Finally, the fixed-depth and active-depth simulations are repeated with one additional release date on November 1 in order to investigate how retention rates would be affected if the larvae emerged after the gyre had fully broken down. This is not repeated for the full-model set-up, as cold winter temperatures would lead to an unrealistically high PLD. It should be stressed that no larvae are believed to hatch at this time in reality, and the extra release date is included only to study the influence of the gyre on dispersal.

Summaries of the particle retention rates, dispersal distances and connectivity statistics are presented for each individual model run. The 'local retention rate' is defined here as the percent of particles that settled upon the same muddy sediment region from which they were released. The 'bounded retention rate' is defined here as the percent of particles that remained within the bounded western Irish Sea region 
(Fig. 1b) at the end of their PLD, but did not necessarily settle upon the muddy sediments. This value is only presented for particles seeded in the western Irish Sea. The bounded retention rate is therefore perhaps a better measure of retention in a more general context, but the local retention rate is more relevant to $N$. norvegicus. Particle transport distances are calculated as the great-circle distance between the initial location and settlement sites.

\section{RESULTS}

\section{Hydrodynamic model output}

Simulated peak sea-surface temperatures in the western Irish Sea in 2005 rose from $\sim 8^{\circ} \mathrm{C}$ in early April to $14.5^{\circ} \mathrm{C}$ in August (Fig. 3a). Thermal stratification gradually developed over this period, and surface to bottom temperature differences reached $5^{\circ} \mathrm{C}$ in July. The water column returned to a vertically mixed state in mid-October.

Residual sub-surface circulation was cyclonic in the western Irish Sea during April; however, mean velocities were slow at this point (generally $<0.05 \mathrm{~m} \mathrm{~s}^{-1}$ ). The northward component of the gyre on the eastern flank of the muddy sediment region developed first, with peak flows reaching $0.1 \mathrm{~m} \mathrm{~s}^{-1}$ in May, whilst the southward return flow on the western flank remained considerably slower until June (Fig. 3c). Mean velocities reached their peak $\left(0.2 \mathrm{~m} \mathrm{~s}^{-1}\right)$ during August and the gyre was almost entirely broken down by late October. The simulated temperature and velocity fields are in good general agreement with the observations of Horsburgh et al. (2000); however the model predicts lower peak surface temperatures and slightly weaker stratification. It is not clear whether these minor differences are due to inter-annual variability or model performance.

Greater seasonal variability was found in the eastern Irish Sea, where surface temperatures ranged from $\sim 6^{\circ} \mathrm{C}$ in early April to $16^{\circ} \mathrm{C}$ in August (Fig. 3b); however thermal stratification was somewhat weaker than in the western Irish Sea. Bottom flow in this region was generally southward and weak (on the order of $0.01 \mathrm{~m} \mathrm{~s}^{-1}$ ), whereas surface circulation appeared to be highly variable. However, the long-term average surface flow was predominantly northwards over the eastern $N$. norvegicus group. This is broadly consistent with the characterisation of eastern Irish Sea circulation by Howarth (1984).

\section{Fixed-depth particles}

Dispersal distance distributions were positively skewed for all model set-ups, release dates and sites (Fig. 4), and were bimodal in some cases. As these distributions were highly non-normal, median dispersal distances are presented (Table 1) rather than mean values, and non-parametric Kruskal-Wallis tests were conducted rather than ANOVA to confirm differences between distributions.

The gyre was the dominant influence upon longterm fixed-depth particle transport in the western Irish Sea and cyclonic trajectories were clearly visible (Fig. 5), even amongst particles released on the earliest release date. Across all 6 spring release dates an average of $93 \%$ of all fixed-depth particles were retained within the bounded western Irish Sea region (Table 2). The overwhelming majority of the remaining particles were advected into the North Channel (6.3\% of the total), although in the last 2 spring release dates these were outnumbered by particles advected into the eastern Irish Sea. There was a product-moment correlation coefficient of 0.90 between bounded retention rate and day-of-year release date during this period, indicating a clear increase in retention with gyre strength. Furthermore, the November bounded retention rate was lower than that of all but the first spring release date. These simulations are therefore in good general agreement with the drifting buoy observations of Horsburgh et al. (2000), and they support the hypothesis that the seasonal gyre increases the likelihood that a passive object fixed at the depth of the thermocline will remain within the western Irish Sea, and that this effect is more pronounced as the gyre strength develops.

Table 1. Median horizontal distance $(\mathrm{km})$ between initial and final particle locations, separated according to release site, model set-up and release date. na: not applicable

\begin{tabular}{|c|c|c|c|c|c|c|c|}
\hline \multirow{2}{*}{$\begin{array}{l}\text { Set-up } \\
\text { Release date: }\end{array}$} & \multicolumn{7}{|c|}{ Distance $(\mathrm{km})$} \\
\hline & 15 Apr & 25 Apr & 5 May & 15 May & 25 May & 4 Jun & $1 \mathrm{Nov}$ \\
\hline \multicolumn{8}{|c|}{ Western Irish Sea } \\
\hline Fixed-depth & 38.7 & 37.8 & 39.0 & 38.2 & 38.0 & 42.2 & 48.0 \\
\hline Active-depth & 45.0 & 43.4 & 34.5 & 45.5 & 50.5 & 59.9 & 49.2 \\
\hline Full-model & 46.7 & 47.0 & 38.0 & 49.5 & 54.9 & 59.4 & na \\
\hline \multicolumn{8}{|c|}{ Eastern Irish Sea } \\
\hline Fixed-depth & 39.0 & 40.1 & 29.1 & 35.7 & 33.1 & 29.3 & na \\
\hline Active-depth & 26.4 & 24.7 & 26.1 & 30.6 & 22.6 & 21.7 & na \\
\hline Full-model & 31.9 & 25.5 & 25.4 & 28.9 & 20.7 & 22.1 & na \\
\hline
\end{tabular}




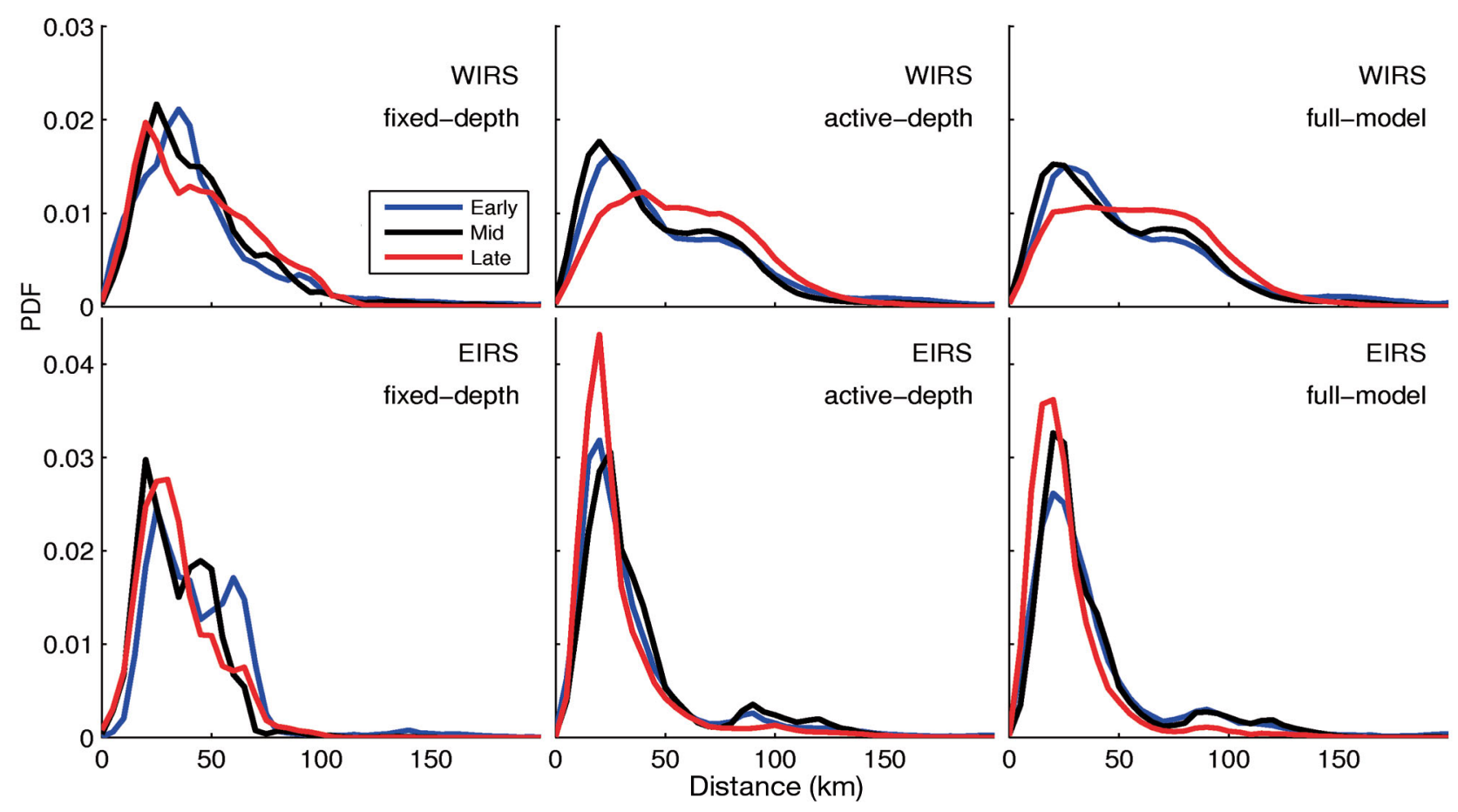

Fig. 4. Probability density function (PDF) of particle transport distance from early (15 and 25 April), mid (5 and 15 May) and late (25 May and 4 June) $N$. norvegicus spawning dates in the western (WIRS) and eastern (EIRS) Irish Sea. Particle transport distance data are placed into $5 \mathrm{~km}$ bins. Distances greater than $200 \mathrm{~km}$ were extremely rare and are not shown

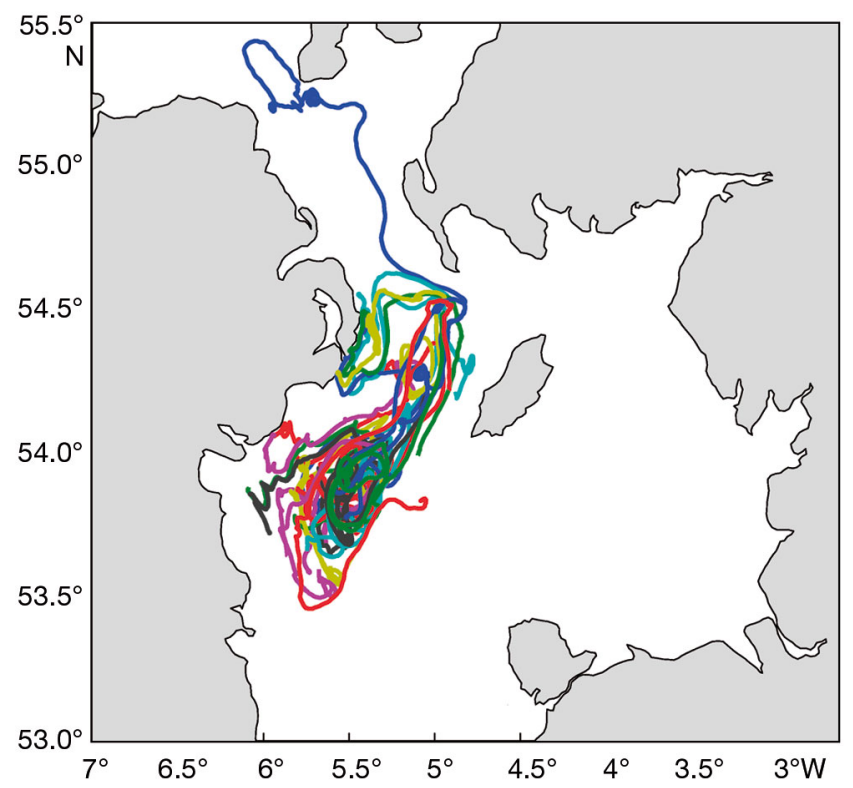

Fig. 5. Trajectories of a random sample of 24 particles released from the Irish Sea in the fixed-depth simulations $(4$ particles from each spring release date). Trajectories have been passed through a central moving average filter to reduce the signal from semi-diurnal tidal advection. Colours are for visual identification of individual trajectories and do not denote any property
The average local retention rate in the western Irish Sea was $42 \%$ (Table 3); therefore fewer than half of the particles that remained within the western Irish Sea actually returned to the muddy sediments. There is a clear spatial variability in local retention rates (Fig. 6); particles released from the centre of the region had almost a $100 \%$ retention rate, whereas particles released from the edges of the muddy sediments were far less likely to return. Although the November local retention rate was somewhat lower $(37 \%)$, there was no linear correlation between release date (gyre strength) and local retention rates over the 6 spring release dates. The results suggest that the gyre does not have a spatially uniform effect upon local retention rates, as the spring releases generally had greater local retention rates in the central and eastern parts of the western Irish Sea site, but lower retention rates on the northern and western flanks (Fig. 7a). On average, 1.0\% of particles released from the western Irish Sea over the first half of the spring release period settled upon the North Channel muddy sediments (Table 3); however this rate was strongly diminished over the following releases, and a negligible amount reached the eastern Irish Sea muddy sediment site on any date. 
Table 2. Percent of particles seeded in the western Irish Sea that remained within the bounded region at the end of their pelagic larval duration (bounded retention rate), separated according to release date and model set-up. na: not applicable

\begin{tabular}{|lccccccc|}
\hline \multirow{2}{*}{$\begin{array}{l}\text { Set-up } \\
\text { Release date: }\end{array}$} & 15 Apr & 25 Apr & 5 May & 15 May & 25 May & 4 Jun & 1 Nov \\
\hline Fixed-depth & 82.8 & 91.3 & 93.5 & 95.6 & 95.4 & 97.9 & 83.5 \\
Active-depth & 70.2 & 82.7 & 88.6 & 86.8 & 85.6 & 80.7 & 84.0 \\
Full-model & 73.6 & 79.8 & 86.7 & 85.0 & 81.5 & 83.3 & na \\
\hline
\end{tabular}

Table 3. Connectivity table detailing the percentage of particles released from a particular region (initial site) that landed on each muddy sediment region (settlement site). Particles are separated according to model set-up (fixeddepth, active-depth, full-model), initial site and release date. Site abbreviations - WIRS: western Irish Sea; EIRS: eastern Irish Sea; NC: North Channel

\begin{tabular}{|c|c|c|c|c|c|c|c|}
\hline \multirow{2}{*}{$\begin{array}{l}\text { Initial site } \\
\text { Release date: }\end{array}$} & \multirow{2}{*}{$\begin{array}{l}\text { Settlement } \\
\text { site }\end{array}$} & \multicolumn{6}{|c|}{ Particles settled (\%) } \\
\hline & & $15 \mathrm{Apr}$ & 25 Apr & 5 May & 15 May & 25 May & 4 Jun \\
\hline \multicolumn{8}{|l|}{ Fixed-depth } \\
\hline \multirow[t]{3}{*}{ WIRS } & WIRS & 43.99 & 40.48 & 43.76 & 36.02 & 49.00 & 41.37 \\
\hline & EIRS & 0.00 & 0.00 & 0.00 & 0.01 & 0.01 & 0.00 \\
\hline & $\mathrm{NC}$ & 0.87 & 1.09 & 1.01 & 0.33 & 0.08 & 0.07 \\
\hline \multirow[t]{3}{*}{ EIRS } & WIRS & 0.10 & 0.02 & 0.00 & 0.03 & 0.08 & 0.02 \\
\hline & EIRS & 1.51 & 0.79 & 3.15 & 3.14 & 2.64 & 3.38 \\
\hline & $\mathrm{NC}$ & 0.69 & 0.70 & 0.00 & 0.06 & 0.03 & 0.00 \\
\hline \multicolumn{8}{|l|}{ Active-depth } \\
\hline \multirow[t]{3}{*}{ WIRS } & WIRS & 27.19 & 32.74 & 39.98 & 34.28 & 33.14 & 24.38 \\
\hline & EIRS & 0.00 & 0.01 & 0.00 & 0.00 & 0.00 & 0.00 \\
\hline & $\mathrm{NC}$ & 0.72 & 0.65 & 0.14 & 0.24 & 0.09 & 0.14 \\
\hline \multirow[t]{3}{*}{ EIRS } & WIRS & 0.28 & 0.30 & 0.82 & 0.66 & 0.30 & 0.15 \\
\hline & EIRS & 1.91 & 7.51 & 4.12 & 2.42 & 0.77 & 2.28 \\
\hline & $\mathrm{NC}$ & 0.07 & 0.02 & 0.01 & 0.02 & 0.02 & 0.00 \\
\hline \multicolumn{8}{|l|}{ Full-model } \\
\hline \multirow[t]{3}{*}{ WIRS } & WIRS & 23.34 & 27.65 & 34.16 & 33.11 & 25.82 & 23.30 \\
\hline & EIRS & 0.00 & 0.00 & 0.00 & 0.00 & 0.00 & 0.00 \\
\hline & $\mathrm{NC}$ & 1.41 & 0.41 & 0.17 & 0.31 & 0.12 & 0.11 \\
\hline \multirow[t]{3}{*}{ EIRS } & WIRS & 0.99 & 0.49 & 0.76 & 0.65 & 0.26 & 0.06 \\
\hline & EIRS & 1.86 & 10.64 & 3.51 & 3.19 & 1.80 & 1.38 \\
\hline & $\mathrm{NC}$ & 0.25 & 0.00 & 0.03 & 0.02 & 0.01 & 0.00 \\
\hline
\end{tabular}

ticles were locally retained, reflecting the smaller size of the muddy sediment region. Local retention rates were much more variable in the eastern Irish Sea (Table 3), for example, particles released on May 5 were almost 4-fold more likely to be retained than those released on April 25 . Some particle exchange from the eastern Irish Sea to the North Channel muddy sediments occurred over the first 2 release dates $(<1 \%)$, but all other exchange from the eastern Irish Sea was highly limited $(\leq 0.1 \%)$.

\section{Active-depth particles}

In the active-depth simulations, $82 \%$ of particles seeded in the western Irish Sea during spring were retained within the bounded region (Table 2 ); however only $32 \%$ settled upon the western Irish Sea muddy sediments (Table 3 ). Therefore, vertical migration led to a considerable reduction to both the bounded and local retention rates in this region. Dispersal distances were also much greater with this model set-up, with a median value of $47 \mathrm{~km}$ across all 6 spring releases. There was no evidence that the gyre promotes retention of vertically migrating particles, as both the bounded and local retention rates were greatest amongst particles that were released during the middle of the hatching period (Tables 2 \& 3), and this coincided

The overall median particle transport distance in the western Irish Sea during spring was $39 \mathrm{~km}$, although $4.9 \%$ of particles were dispersed $100 \mathrm{~km}$ or greater (Fig. 4), and the greatest recorded distances exceeded $270 \mathrm{~km}$. Whilst there was no clear trend in dispersal distance as the gyre developed (Table 1), the median distance of the November release was considerably greater than that of all 6 spring releases. A Kruskal-Wallis test confirmed that the differences between the dispersal distances of different release dates were significant $\left(\chi^{2}=1.3 \times 10^{3}, \mathrm{df}=5, \mathrm{p}<0.001\right)$.

In the eastern Irish Sea the overall median transport distance was slightly shorter at $34 \mathrm{~km}$ due to the weaker mean circulation; however only $2.4 \%$ of par- with shorter dispersal distances (Table 1). Differences in dispersal distances between release dates were significant in a Kruskal-Wallis test $\left(\chi^{2}=2.8 \times\right.$ $\left.10^{4}, \mathrm{df}=5, \mathrm{p}<0.001\right)$. Furthermore, the local retention rate during the November release scenario was $39 \%$, which is considerably greater than the average value during spring. There were some similarities with the fixed-depth particles, however, as the greatest local retention rates were found amongst particles released from the centre of the muddy sediments (Fig. 6), and the majority of particles that left the bounded western Irish Sea region altogether were advected into the North Channel $(17 \%$ of the total during spring). 

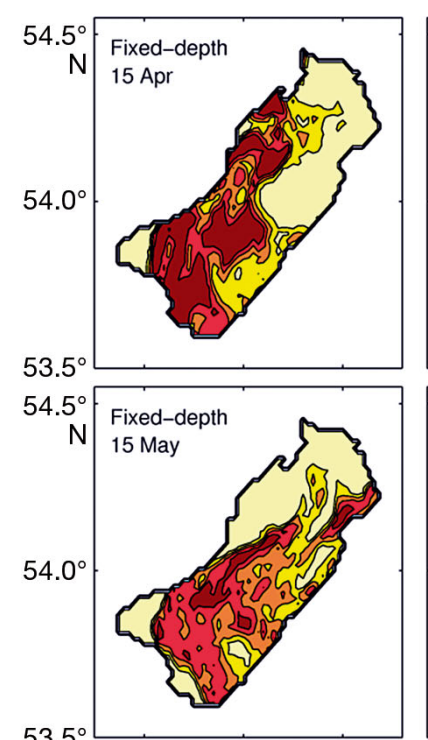

$53.5^{\circ}$

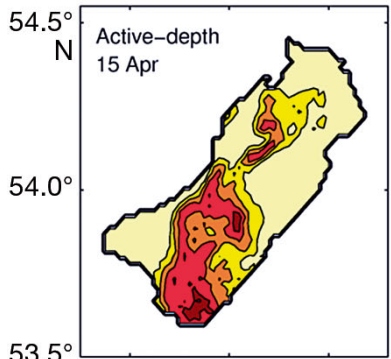

$53.5^{\circ}$
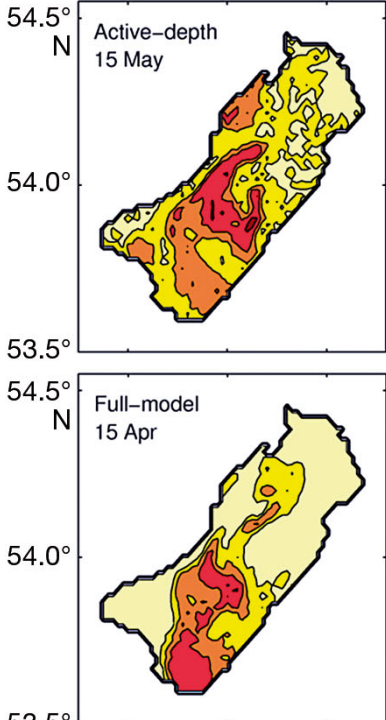

$53.5^{\circ}$

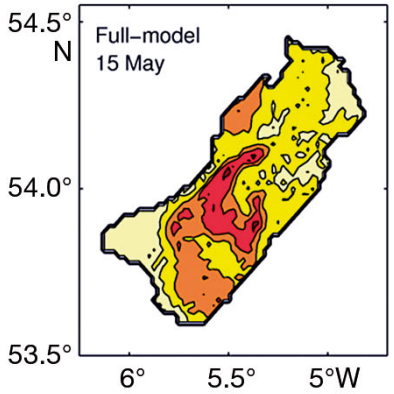

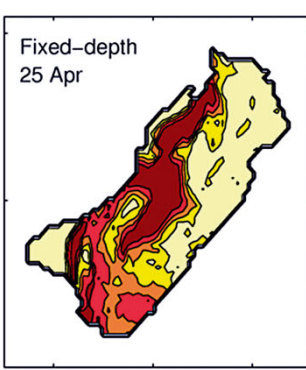
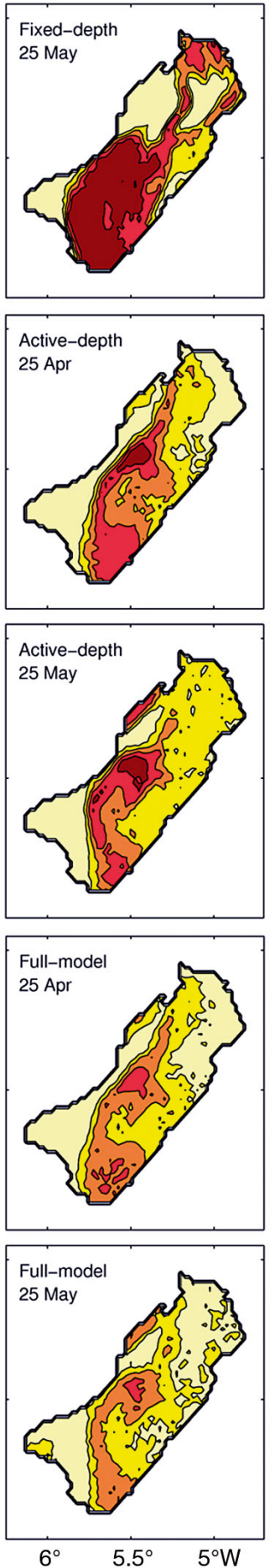
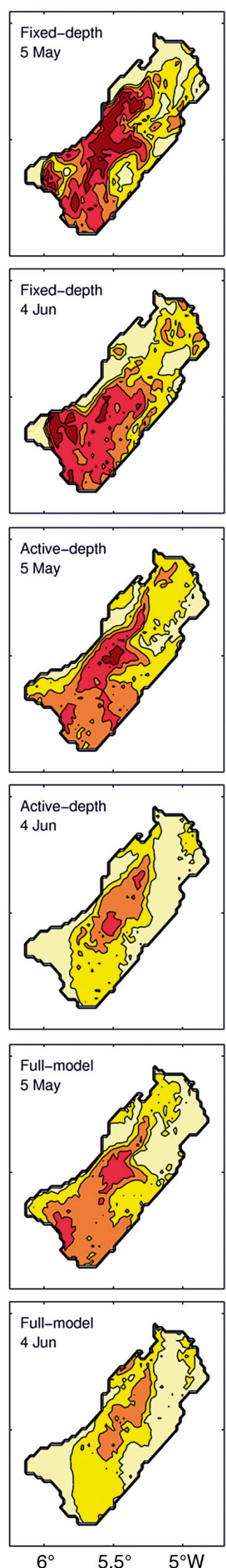

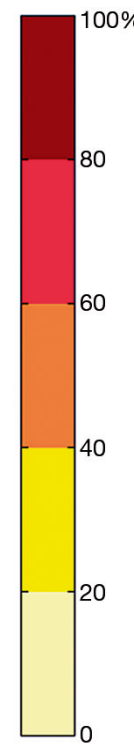

Fig. 6. Particle retention rates (denoted by colour) in the western Irish Sea, mapped onto the POLCOMS Irish Sea grid according to particle release site, and separated according to model set-up (fixed-depth, activedepth, full-model) and release date (15, 25 April; 5, 15, 25 May; 4 June)

By contrast, active-depth particles released during spring in the eastern Irish Sea had an overall median dispersal distance of $25 \mathrm{~km}$, which is $9 \mathrm{~km}$ shorter than the distance amongst fixed-depth particles, and the average local retention rate was somewhat greater at $3.2 \%$. Once again the results showed a high degree of temporal variability in the eastern Irish Sea. Connectivity between distinct regions was highly limited. Perhaps the most notable distinction between the model set-ups was the greater number of particles from the eastern Irish Sea settling upon the western Irish Sea muddy sediments in the active-depth set-up, peaking at $0.8 \%$ on the May 5 release.

\section{Full-model particles}

The mean PLD of western Irish Sea particles reduced from $70 \mathrm{~d}$ on 15 April to $59 \mathrm{~d}$ on 4 June. The eastern Irish Sea displayed even greater seasonal variability, with the mean PLD reducing from 67 to $44 \mathrm{~d}$ over the hatching period, due to the wider range in water temperature. The PLD of particles that were released closer to the warmer Irish coastal waters on the western flank of the western Irish Sea muddy sediments was typically around $20 \mathrm{~d}$ shorter than the PLD in the central and eastern regions of the same site 

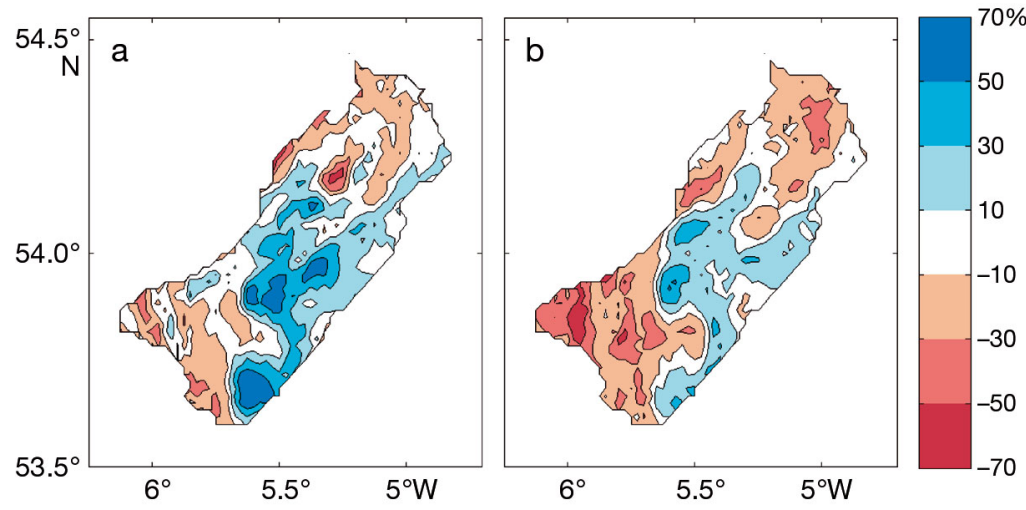

Fig. 7. Average spring local retention rate minus the November local particle retention rate in the western Irish Sea. Particles are mapped onto the POLCOMS grid according to initial location. Positive values indicate that the seasonal gyre aids local retention in that region; negative values indicate the gyre inhibits local retention. (a) Fixed-depth model, (b) active-depth model
Full-model particle exchange rates were generally similar to those in the active-depth simulations; however there was a slightly greater mean rate of transport from the eastern Irish Sea to the western population (Table 3). Once again, this limited connectivity was greatest in the initial part of the hatching period, and transport in the reverse direction remained negligible.

\section{DISCUSSION}

The dispersal of marine larvae by ambient circulation is fundamental to population dynamics, and it is an important consideration in the effec-
(Fig. 8). There was also a small zonal PLD gradient in the eastern Irish Sea; particles that were released closer to the English coastline typically had a PLD of around $5 \mathrm{~d}$ shorter than those released further offshore.

In the full-model simulations the average bounded and local retention rates in the western Irish Sea were 82 and $28 \%$, respectively (Tables $2 \& 3$ ), and the overall median dispersal distance was $50 \mathrm{~km}$ (Table 1 , Fig. 4). Therefore the inclusion of a temperaturedependent PLD did not affect the proportion of particles that remained within the wider western Irish Sea, but it did lead to a small reduction in the proportion of particles that were able to settle upon the muddy sediments, and a slight increase in dispersal distances. Seasonal and spatial trends in retention rates remained the same as in the active-depth simulations, with the greatest local retention amongst particles released from the centre of the western Irish Sea population, and in the middle of the hatching period (Fig. 6). Differences between the dispersal distances of different release dates were significant in a Kruskal-Wallis test $\left(\chi^{2}=1.6 \times 10^{4}, \mathrm{df}=5, \mathrm{p}<\right.$ $0.001)$. On average, $3.7 \%$ of particles were retained locally in the eastern Irish Sea, which is somewhat greater than the rate in the active-depth simulations, although the overall median dispersal distance was almost unchanged. tive design of marine protected areas (Cowen \& Sponaugle 2009). This is particularly true for benthic invertebrate species such as Nephrops norvegicus, as they typically remain sessile or sedentary throughout their adult life. Understanding the drivers of larval dispersal and the factors that influence population connectivity is therefore an important challenge for marine ecologists.

The western Irish Sea seasonal gyre is a widely cited example of a regional dynamical system that affects larval dispersal (e.g. Hill et al. 1996, DickeyCollas et al. 1997, Hill et al. 1997). The influence of the gyre upon $N$. norvegicus is particularly important from an ecological perspective due to the intense
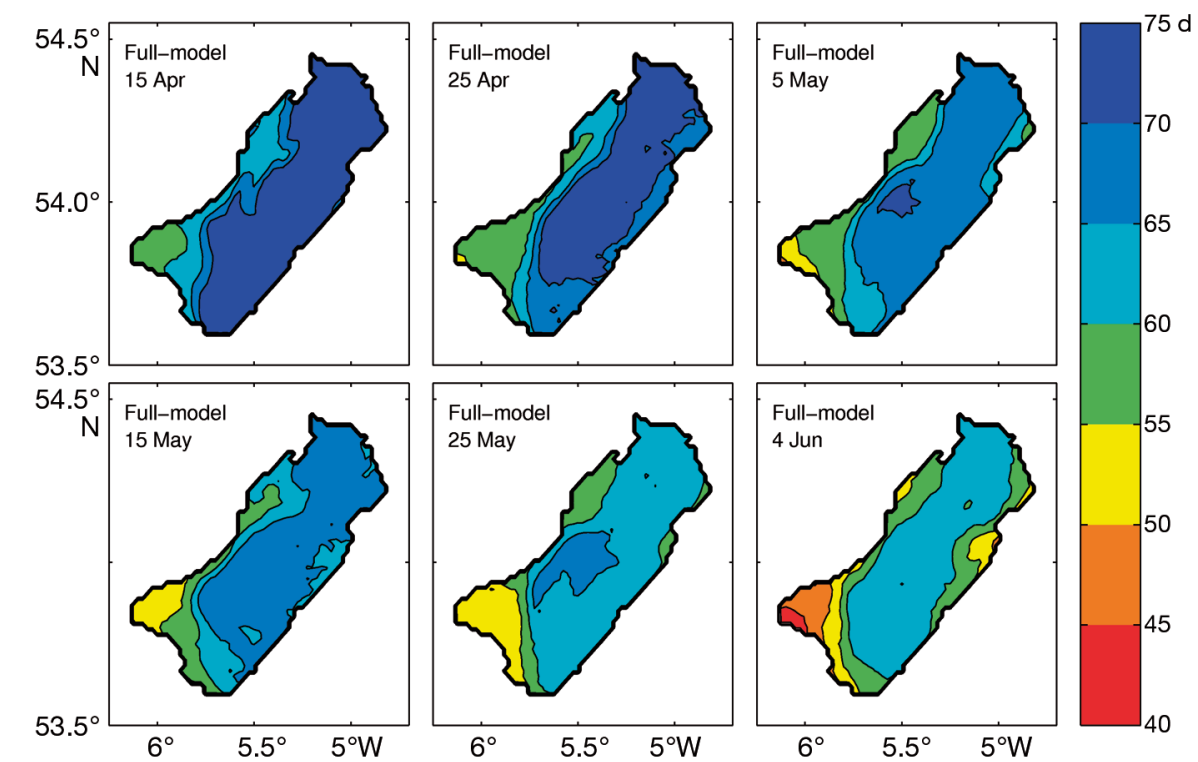

Fig. 8. Mean pelagic larval duration (d) of particles in the western Irish Sea. Particles are mapped onto the POLCOMS Irish Sea grid according to initial location 
trawling efforts and the spatial distribution of the requisite muddy sediments in relation to the gyre. Despite this, previous studies have largely neglected certain aspects of $N$. norvegicus larval behaviour, such as sediment requirements, vertical swimming, or appropriate PLD. As recent modelling work suggests that the dynamical characteristics of the gyre may be changing (Olbert et al. 2011), it is now imperative that the effect of the gyre on $N$. norvegicus larval dispersal is properly understood. This investigation has thoroughly tested the validity of the hypothesis that the gyre acts as an effective retention mechanism for $N$. norvegicus larvae.

The results of this investigation suggest that the seasonal gyre does reinforce retention of larvae within the wider western Irish Sea region, on the condition that the larvae remain fixed at the depth of peak gyral flow. However, approximately half of these fixed-depth larvae will fall outside of the muddy sediments at the end of their larval phase (assuming a PLD of around $60 \mathrm{~d}$ ), and the local retention rate does not appear to increase with gyre strength. There is therefore little evidence that the gyral circulation promotes local recruitment amongst fixed-depth larvae that require muddy sediments for successful settlement.

The influence of the gyre is not spatially uniform across the western Irish Sea. The results suggest that the gyral system reinforces local retention amongst larvae that originate from the central part of the muddy sediments, and diminishes retention rates around the periphery. In reality, larval densities are greatest in the centre of the region; therefore the results of this investigation may be consistent with the gyre retention hypothesis of Hill et al. (1996) after accounting for this spatial variability. Future modelling investigations should aim to utilise a nonuniform initial particle distribution to confirm whether this is the case.

On average, vertically migrating particles were dispersed $10 \mathrm{~km}$ farther, and were $25 \%$ less likely to be locally retained, relative to fixed-depth retention rates. This can be explained by the fact that the gyre is vertically confined to a relatively narrow band around the thermocline, and vertical migration will increase the likelihood of escaping this circulation. Shear diffusion and vertically sheared tidal currents may introduce further net transport away from the adult grounds. Furthermore, retention rates amongst vertically migrating particles were greater in May than June despite the weaker gyral flow. Vertical migration is clearly a significant influence upon larval dispersal in shelf sea gyres, and this investigation finds no evidence that gyral circulation promotes local retention of vertically migrating larvae. Diel vertical migration is common amongst many meroplanktonic larvae and holoplanktonic organisms such as copepods, and there are several proposed explanations for the adaptive significance of this behaviour, including evasion of visually dependent predators (Zaret \& Suffern 1976, Gliwicz 1986), metabolic benefits (Mclaren 1963) and decreasing exposure to damaging solar radiation (Leech \& Williamson 2001). It is certainly possible that one of these explanations could hold for $N$. norvegicus larvae. Whilst this investigation cannot determine the reason for vertical migration of $N$. norvegicus larvae, the results do suggest that larvae in the western Irish Sea do not migrate for the purpose of local retention.

By contrast, in the eastern Irish Sea, vertical migration appears to reduce dispersal distance and increase retention rates. This can be explained by the fact that migrations between a northward surface mean flow and a southward bottom flow will ultimately reduce net advection. $N$. norvegicus larvae released from the eastern Irish Sea are typically advected much shorter distances; however, larval retention rates are considerably lower due to the smaller habitat area. Retention rates in the eastern Irish Sea display considerable short-term variability, which suggests that meteorological forcing may play a significant role in determining local retention. A small minority of larvae from both sites will likely be dispersed over distances $>100 \mathrm{~km}$. Peak dispersal distances are slightly lower than those reported for fish eggs and larvae in the Irish Sea by van der Molen et al. (2007); however this is explained by the fact that $N$. norvegicus have a shorter PLD.

$N$. norvegicus PLD varies considerably both spatially and temporally due to changes in water temperature. Larvae that hatch in the central and western parts of the western Irish Sea population during April typically spend twice as long in the plankton as larvae that hatch from the coastal areas during July. In the western Irish Sea the mean PLD was generally greater than the $60 \mathrm{~d}$ assumed for the first 2 model set-ups, and this resulted in an increase in dispersal distances and a reduction in retention rates.

Whilst investigating the influence of vertical migration strategy on larval retention in the Irish Sea, Emsley et al. (2005) concluded that DVM supported particle retention by increasing the probability of larvae becoming entrained within the gyre. The results of the current study would initially appear to directly oppose this conclusion. The discrepancy between the findings could be for a number of reasons. The com- 
putational advances of the past decade allowed the use of more advanced numerical methods in the current investigation (notably RK4 particle advection, significantly greater number of particles, shorter time steps and the introduction of stochastic vertical diffusion). Furthermore, the current study is focused upon $N$. norvegicus; therefore a more realistic PLD is adopted (rather than 30 or $90 \mathrm{~d}$ ), and a particle is considered 'retained' if it returns to the muddy sediments, rather than if it remains within the model boundaries. Vertical swimming behaviour is also parameterised differently, and the passive particle depths are not equal, therefore the findings of the 2 investigations are perhaps not mutually exclusive. Several other modelling studies report that vertical migration has a significant effect on larval (or fish egg) transport in the Irish Sea (e.g. Fox et al. 2006, van der Molen et al. 2007, Robins et al. 2013); however these studies largely focus upon species with coastal or estuarine hatching sites and nursery grounds, so it is more difficult to make direct comparisons to an offshore benthic species such as $N$. norvegicus.

In all simulations, local retention rates were significantly greater amongst particles released from the central part of the gyre, whereas those released from the periphery were highly likely to be lost from the system. This suggests that the adult $N$. norvegicus that inhabit the central part of the muddy sediments may play the most important role in sustaining the population. Therefore, if a marine protected area was considered for a gyral system such as the western Irish Sea, the results of this investigation suggest that it may be more ecologically effective if the centre of the gyre was prioritised.

Olbert et al. (2011) proposed that changing atmospheric conditions are resulting in stronger cyclonic circulation in the western Irish Sea, but a shorter gyre duration and a delay in the peak flow, coupled with a decrease in the residence time. It is difficult to determine exactly how the $N$. norvegicus population would be affected by a change in the strength or duration of the gyre. The results of this investigation suggest that the population is not as reliant upon the gyre for self sustainability as previously thought; therefore the population may not be sensitive to small changes in the dynamical properties of the gyre. However, it is worth highlighting that the greatest local retention rates are found during early May, and this period corresponds with the peak hatching time of N. norvegicus larvae (Dickey-Collas et al. 2000a). Any delay in the onset of the gyre could upset this synchronisation, unless it is matched by a similar delay in hatching time. The decrease in residence time suggests that the region is becoming less retentive, and this could lead to greater losses of larvae from the system. Further work should aim to investigate how the long-term inter-annual variability of the gyre will affect larval retention.

Overall, this investigation is in agreement with the conclusion of van der Molen et al. (2007), that the capability of the western Irish Sea gyre to retain larvae appears to be relatively weak. This conclusion is supported further by larval surveys (Hillis 1974, White et al. 1988) that clearly show N. norvegicus larvae outside the muddy sediment regions, suggesting some loss from the system due to mean advection, although Nichols et al. (1987) proposed that this could be due to adults living outside the muddy substrate that is recognised as the boundary of the $N$. norvegicus population. It appears that whilst Horsburgh et al. (2000) provides an excellent and thorough assessment of the physical and dynamical properties of the western Irish Sea gyre, the fixed-depth drifters neglect too many factors for their trajectories to be representative of $N$. norvegicus larvae. This should serve as a warning for marine ecologists to exercise extreme caution whenever attempting to deduce information about larval dispersal from passive drifter observations. Although it is also important to take care when attempting to assess population connectivity from numerical simulations alone, these simulations suggest that the distinct $N$. norvegicus sites largely rely upon local recruitment of larvae, despite some evidence of highly limited 1 -way connectivity in a pattern that broadly reflects the mean circulation in the Irish Sea.

Acknowledgements. J.J.C.P. was supported by Natural Environment Research Council (NERC) studentship funding (NE/I528042/1). The authors thank the 4 anonymous reviewers for their helpful comments.

\section{LITERATURE CITED}

Arakawa A, Lamb VR (1977) Computational design of the basic dynamical processes of the UCLA generic circulation model. Methods Comput Phys 17:173-265

Bowden K (1950) Processes affecting the salinity of the Irish Sea. Geophys J Int (Suppl 2: Mon Not R Astron Soc) 6: S63-S90

Briggs RP, Armstrong MJ, Dickey-Collas M, Allen M, McQuaid N, Whitmore J (2002) The application of fecundity estimates to determine the spawning stock biomass of Irish Sea Nephrops norvegicus (L.) using the annual larval production method. ICES J Mar Sci 59:109-119

Canuto VM, Howard A, Cheng Y, Dubovikov MS (2001) Ocean turbulence. Part I: One-point closure model- 
Momentum and heat vertical diffusivities. J Phys Oceanogr 31:1413-1426

- Colella P, Woodward PR (1984) The Piecewise Parabolic Method (PPM) for gas-dynamical simulations. J Comput Phys 54:174-201

Cowen RK, Sponaugle S (2009) Larval dispersal and marine population connectivity. Annu Rev Mar Sci 1:443-466

$>$ Cronin TW, Forward RB (1979) Tidal vertical migration - an endogenous rhythm in estuarine crab larvae. Science 205:1020-1022

Cushing DH (1951) The vertical migration of planktonic Crustacea. Biol Rev Camb Philos Soc 26:158-192

$>$ Dickey-Collas M, Brown J, Fernand L, Hill AE, Horsburgh KJ, Garvine RW (1997) Does the western Irish Sea gyre influence the distribution of pelagic juvenile fish? J Fish Biol 51:206-229

> Dickey-Collas M, Briggs RP, Armstrong MJ, Milligan SP (2000a) Production of Nephrops norvegicus larvae in the Irish Sea. Mar Biol 137:973-981

> Dickey-Collas M, McQuaid N, Armstrong MJ, Allen M, Briggs RP (2000b) Temperature-dependent stage durations of Irish sea Nephrops larvae. J Plankton Res 22: 749-760

Emsley SM, Tarling GA, Burrows MT (2005) The effect of vertical migration strategy on retention and dispersion in the Irish Sea during spring-summer. Fish Oceanogr 14: 161-174

- Fairall CW, Bradley EF, Hare JE, Grachev AA, Edson JB (2003) Bulk parameterization of air-sea fluxes: updates and verification for the COARE algorithm. J Clim 16: 571-591

Farmer ASD (1975) Synopsis of biological data on the Norway lobster Nephrops norvegicus (Linnaeus, 1758). FAO Fish Synop FIRS/S112

Forward RB, Cronin TW, Stearns DE (1984) Control of diel vertical migration-photoresponses of a larval crustacean. Limnol Oceanogr 29:146-154

$>$ Fox CJ, McCloghrie P, Young EF, Nash RDM (2006) The importance of individual behaviour for successful settlement of juvenile plaice (Pleuronectes platessa L.): a modelling and field study in the eastern Irish Sea. Fish Oceanogr 15:301-313

> Fox CJ, McCloghrie P, Nash RDM (2009) Potential transport of plaice eggs and larvae between two apparently selfcontained populations in the Irish Sea. Estuar Coast Shelf Sci 81:381-389

Gliwicz MZ (1986) Predation and the evolution of vertical migration in zooplankton. Nature 320:746-748

Hill AE (1991) Vertical migration in tidal currents. Mar Ecol Prog Ser 75:39-54

- Hill AE (1996) Spin-down and the dynamics of dense pool gyres in shallow seas. J Mar Res 54:471-486

> Hill AE, Durazo R, Smeed DA (1994) Observations of a cyclonic gyre in the western Irish Sea. Cont Shelf Res 14: 479-490

Hill AE, Brown J, Fernand L (1996) The western Irish Sea gyre: A retention system for Norway lobster (Nephrops norvegicus)? Oceanol Acta 19:357-368

Hill AE, Brown J, Fernand L (1997) The summer gyre in the western Irish Sea: shelf sea paradigms and management implications. Estuar Coast Shelf Sci 44:83-95

Hillis JP (1974) Field observations on larvae of the Dublin Bay prawn Nephrops norvegicus (L.) in the western Irish Sea. Ir Fish Investig B 13:1-24

$>$ Holt JT, James ID (2001) An $s$ coordinate density evolving model of the northwest European continental shelf: 1. Model description and density structure. J Geophys Res 106:14015-14034

Horsburgh KJ, Hill AE (2003) A three-dimensional model of density-driven circulation in the Irish Sea. J Phys Oceanogr 33:343-365

> Horsburgh KJ, Hill AE, Brown J, Fernand L, Garvine RW, Angelico MMP (2000) Seasonal evolution of the cold pool gyre in the western Irish Sea. Prog Oceanogr 46:1-58

Howarth MJ (1984) Currents in the eastern Irish Sea. Oceanogr Mar Biol Annu Rev 22:11-53

> Hunter JR, Craig PD, Phillips HE (1993) On the use of random-walk models with spatially-variable diffusivity. J Comput Phys 106:366-376

> James ID (1996) Advection schemes for shelf sea models. J Mar Syst 8:237-254

Kingsford et al. (2002) Sensory environments, larval abilities and local self-recruitment. Bull Mar Sci 70 (1 Suppl): 309-340

Knights AM, Crowe TP, Burnell G (2006) Mechanisms of larval transport: vertical distribution of bivalve larvae varies with tidal conditions. Mar Ecol Prog Ser 326:167-174

> Leech DM, Williamson CE (2001) In situ exposure to ultraviolet radiation alters the depth distribution of Daphnia. Limnol Oceanogr 46:416-420

Lindley JA, Williams R, Conway DVP (1994) Variability in dry-weight and vertical distributions of decapod larvae in the Irish Sea and North Sea during the Spring. Mar Biol 120:385-395

> McLaren IA (1963) Effects of temperature on growth of zooplankton, and the adaptive value of vertical migration. J Fish Res Board Can 20:685-727

> Nichols JH, Bennett DB, Symonds DJ, Grainger R (1987) Estimation of the stock size of adult Nephrops norvegicus (L.) from larvae surveys in the western Irish Sea in 1982. J Nat Hist 21:1433-1450

> Nicolle A, Dumas F, Foveau A, Foucher E, Thiebaut E (2013) Modelling larval dispersal of the king scallop (Pecten maximus) in the English Channel: examples from the Bay of Saint-Brieuc and the Bay of Seine. Ocean Dyn 63: 661-678

> North EW, Schlag Z, Hood RR, Li M, Zhong L, Gross T, Kennedy VS (2008) Vertical swimming behavior influences the dispersal of simulated oyster larvae in a coupled particle-tracking and hydrodynamic model of Chesapeake Bay. Mar Ecol Prog Ser 359:99-115

North EW, Gallego A, Petitgas P (eds) (2009) Manual of recommended practices for modelling physical-biological interactions during fish early life. ICES Coop Res Rep 295

> O'Connor MI, Bruno JF, Gaines SD, Halpern BS, Lester SE, Kinlan BP, Weiss JM (2007) Temperature control of larval dispersal and the implications for marine ecology, evolution, and conservation. Proc Natl Acad Sci USA 104: 1266-1271

> O'Neill CK, Polton JA, Holt JT, O'Dea EJ (2012) Modelling temperature and salinity in Liverpool Bay and the Irish Sea: sensitivity to model type and surface forcing. Ocean Sci 8:903-913

Olbert AI, Hartnett M, Dabrowski T, Mikolajewicz U (2011) Long-term inter-annual variability of a cyclonic gyre in the western Irish Sea. Cont Shelf Res 31:1343-1356

Phelps JJC, Polton JA, Souza AJ, Robinson LA (2013) Hydrodynamic timescales in a hyper-tidal region of freshwater influence. Cont Shelf Res 63:13-22

Polton JA, Palmer MR, Howarth MJ (2011) Physical and 
dynamical oceanography of Liverpool Bay. Ocean Dyn 61:1421-1439

Powell A, Eriksson SP (2013) Reproduction: life cycle, larvae and larviculture. Adv Mar Biol 64:201-245

$>$ Qiu ZF, Doglioli AM, He YJ, Carlotti F (2011) Lagrangian model of zooplankton dispersion: numerical schemes comparisons and parameter sensitivity tests. Chin J Oceanology Limnol 29:438-445

Robins PE, Neill SP, Gimenez L, Jenkins SR, Malham SK (2013) Physical and biological controls on larval dispersal and connectivity in a highly energetic shelf sea. Limnol Oceanogr 58:505-524

Ross ON, Sharples J (2004) Recipe for 1-D Lagrangian particle tracking models in space-varying diffusivity. Limnol Oceanogr Methods 2:289-302

Shanks AL, Grantham BA, Carr MH (2003) Propagule dispersal distance and the size and spacing of marine reserves. Ecol Appl 13(Suppl):159-169

Simpson JH, Hunter JR (1974) Fronts in the Irish Sea. Nature 250:404-406

Smith R (1987) The biology of larval and juvenile Nephrops norvegicus (L.) in the Firth of Clyde. PhD thesis, University of Glasgow

Smith NP, Stoner AW (1993) Computer-simulation of larval transport through tidal channels - role of vertical migration. Estuar Coast Shelf Sci 37:43-58

Sundelof A, Jonsson PR (2012) Larval dispersal and vertical migration behaviour - a simulation study for short dispersal times. Mar Ecol 33:183-193

Thompson BM, Ayers RA (1989) Laboratory studies on the development of Nephrops norvegicus larvae. J Mar Biol Assoc UK 69:795-801

Umlauf L, Burchard H (2003) A generic length-scale equation for geophysical turbulence models. J Mar Res 61: 235-265

van der Molen J, Rogers SI, Ellis JR, Fox CJ, McCloghrie P (2007) Dispersal patterns of the eggs and larvae of spring-spawning fish in the Irish Sea, UK. J Sea Res 58: 313-330

$>$ Vikebo F, Sundby S, Adlandsvik B, Fiksen O (2005) The combined effect of transport and temperature on distribution and growth of larvae and pelagic juveniles of Arcto-Norwegian cod. ICES J Mar Sci 62:1375-1386

Visser AW (1997) Using random walk models to simulate the vertical distribution of particles in a turbulent water column. Mar Ecol Prog Ser 158:275-281

White RG, Hill AE, Jones DA (1988) Distribution of Nephrops norvegicus (L.) larvae in the western Irish Sea-an example of advective control on recruitment. J Plankton Res 10:735-747

Willis J (2011) Modelling swimming aquatic animals in hydrodynamic models. Ecol Model 222:3869-3887

> Wilson TRS (1974) Cesium-137 as a water movement tracer in the St George's Channel. Nature 248:125-127

$>$ Xing JX, Davies AM (2001) A three-dimensional baroclinic model of the Irish Sea: formation of the thermal fronts and associated circulation. J Phys Oceanogr 31:94-114

> Zaret TM, Suffern JS (1976) Vertical migration in zooplankton as a predator avoidance mechanism. Limnol Oceanogr 21:804-813

Appendix. Vertical migration parameterisation

The weighted parameter $\lambda$ is calculated using the following function of larval stage, time of day and depth in the water column. Here $z$ denotes depth (given in metres, positive $z$ is directed upwards in the water column, reaching 0 at the surface), $P$ is the period of diel vertical migration (i.e. $1 \mathrm{~d}$ ), $t$ denotes time and $\tau$ represents the normalised stage duration.

$$
\lambda= \begin{cases}\tau(1+\sin (2 \pi t / P)-0.2 \alpha) & \text { if stage }=1, \tau<0.5 \\ 0.5(1+\sin (2 \pi t / P)-0.2 \alpha) & \text { if stage }=1, \tau \geq 0.5 \\ 0.5(1+\sin (2 \pi t / P)-0.2 \alpha) & \text { if stage }=2 \\ 0.5(1+\sin (2 \pi t / P)) & \text { if stage }=3, \tau<0.5 \\ (1-\tau)(1+\sin (2 \pi t / P)) & \text { if stage }=3, \tau \geq 0.5\end{cases}
$$

where $\alpha$ is introduced to prevent particles accumulating in the bottom waters during the first 2 larval stages, given by

$$
\alpha=\left\{\begin{array}{l}
1 \text { if } z \leq-40 \mathrm{~m} \\
0 \text { if } z>-40 \mathrm{~m}
\end{array}\right.
$$

Note that in the active-depth simulations, $\tau$ is calculated by assuming a uniform temperature of $9.23^{\circ} \mathrm{C}$, therefore permitting vertical migration using this sub-model whilst still forcing a PLD of $60 \mathrm{~d}$.

Editorial responsibility: Alejandro Gallego, Aberdeen, UK
Submitted: May 30, 2014; Accepted: September 11, 2014 Proofs received from author(s): November 27, 2014 